\title{
CANCER BASICS: HALLMARKS AND METASTASIS
}

\author{
Sukhvinder Singh Sudan \\ Graphic Era deemed to be University, Dehradun, U.K.-248001 \\ Gurpreet Singh \\ Graphic Era deemed to be University, Dehradun, U.K.-248001 \\ Bhavika Batra \\ Graphic Era deemed to be University, Dehradun, U.K.-248001
}

\begin{abstract}
Cancer is a leading cause of death among people all over the world. New studies are everyday being conducted and published across the globe to assist in cancer research and therapeutic development. Hanahan and Weinberg in their review article in 2000 and 2011 have stated some common traits that are shared by all types of cancer referred to as the Hallmarks of Cancer. The following review talks about those hallmarks and the basic process of Metastasis.
\end{abstract}

Keywords - Cancer, Hallmarks, Metastasis.

\section{INTRODUCTION}

Cancer is generally referred to as a group of diseases in which cells undergo uncontrolled proliferation and growth and invading various tissues at distant sites in the body. As cells grow in the body they wear out and grow old and are removed from the bodily system by a process known as apoptosis or programmed cell death [1]. Sometimes this process of apoptosis may go wrong leading to continuous cell proliferation which might be caused due to a wide range of reasons such as mutations. As these cells grow without undergoing programmed cell death, a mass is developed which is called a tumor. These tumors might be benign with no capabilities of invading to different tissues in the body or might be malignant with a capacity to spread across the body (metastasis) [2].

Cancer is known to be the leading cause of death in India as well as across the globe. There are approximately 2.25 million people living with cancer in India with over 1 million cases reported every year with approximately 780,000 deaths. Cervical cancer is a cause of 1 death in women every 8 minutes. Out of every 2 women diagnosed with breast cancer, one dies in India. Mortality rates due to tobacco use are increasing by 3500 everyday. Breast cancer accounts for $14 \%$ of the total cancers diagnosed in women. 1 in 22 and 1 in 60 women are likely to develop breast cancer in their lifetime in urban and rural areas respectively. Lung cancer on the other hand is more prevalent in men with 48,000 cases yearly and causing more than 45,000 mortalities $[5,6]$. The major reason for these high mortality rates has been linked to the late diagnosis of the disease. $70-80 \%$ cases are diagnosed with stage 3 or 4 cancer because of the very little awareness among the population as well as community physicians, lack of screening programs and diagnostic facilities and high costs of treatment. It has been very difficult to implement screening programs because of the lack of workforce of physicians, health care workers and pathologists capable to review the clinical data. The lack of will of workers to work in urban settings has called for an unequal distribution of healthcare facilities across the country [10].

Cancer in itself is a very large subject covering a wide and diverse areas of science that need to be studied in order to take up research. A plethora of complicated as well as simple scientific literature is available on cancer today that is being continuously studies and evaluated. The following review has been written to address the two very basic and important topics in cancer research, that is, Hallmarks of Cancer and Metastasis. The following review has been designed to be compact and easy to provide an understanding to a larger number of public on cancer [11].

\section{The Cellular Hallmarks OF CANCER}

"The Hallmarks of Cancer" was a review article which was first published in 2000 in the journal Cell by Douglas Hanahan and Robert Weinberg. The authors have reviewed the complex data available on cancer and concluded six common underlying traits (later updated to ten in 2011) shared by all types of cancer $[12,13]$.

\section{Cellular Hallmark No. 1: Replicative Immortality}

As a result of the end Replicative problem, normal human cells tend to possess a finite ability to undergo mitosis. The major factor underlying factor for this is the shortening of the ends of the chromosomes (telomeres) after every mitotic division. As the normal human cells reach the Hay flick's limit 


\section{International Journal of Engineering Applied Sciences and Technology, 2020 Vol. 5, Issue 4, ISSN No. 2455-2143, Pages 355-359 \\ Published Online August 2020 in IJEAST (http://www.ijeast.com)}

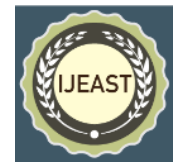

cells can enter the $\mathrm{G}_{0}$ phase of the cell cycle. When we compare these characteristics to that of a cancer cell they are inclined to work differently. Cancers cells have the ability to enormously exceed the Hay flick's limit and thereby continue to undergo mitosis [14]. Cancer cells develop this ability by elongating their telomeres with the help of an enzyme called telomerase. Telomerase assists the cancer cells by extending the chromosomal ends which results in continuing mitotic division [15].

\section{Cellular Hallmark No. 2: Genome Instability}

Normal eukaryotic cells have 23 pairs of chromosomes stored in their nucleus per cycle. During the $\mathrm{S}$ phase of the cell cycle, where DNA synthesis takes place, if a mutation is detected the cell cycle arrests and the mutation is repaired before reentering the cell cycle. The entire process of mutation repair is carried out by tumor suppressor genes. Again cancer cells behave differently and may have any amount of chromosomes per cycle and can undergo mitosis despite having mutations in their DNA [16]. Tumor suppressor genes are the ones that are commonly mutated or lost during the process. Certain genes commonly referred to as oncogenes are over expressed which cause the cells to proliferate uncontrollably. Point mutations, loss of heterozygosity and deletion of regions of chromosomes are the most common gene alterations observed in cancer [17].

\section{Cellular Hallmark No. 3 Evasion of Growth Suppressor signals}

At the cell cycle level, in mitosis of normal cells, the process is tightly governed by pro and anti proliferation signals thereby coordinating cell activities. But due to hallmark no. 2, cancer cells can override the growth suppressor signals in the G1 checkpoint and continue proliferating. As example let us consider retinoblastoma $(\mathrm{Rb})$ and P53 which are both tumor suppressor genes. $\mathrm{Rb}$ is responsible for preventing excessive cell growth by only providing a passage to normal cells during the G1 phase of the cell cycle where as restricting the cell cycle if the cell is not ready to divide [18]. On the other hand p53 is responsible for regulating apoptosis and stops the cell cycle upon detection of DNA damage [19]. It has been observed in major cancer types that these tumor suppressor genes where lost which allowed the cell cycle to progress despite DNA damage [20].

\section{Cellular Hallmark No. 4 Resistance to Apoptosis}

The process of removing aged cells from the body is referred to as apoptosis or programmed cell death. Normal cells have the ability to initiate apoptosis again any kind of cellular stress or DNA damage where as cancer cells avoid apoptosis as they are not sensitive to DNA damage, treatment, growth factor deprivation and similar cellular stresses [21]. Cancer cells also tend to over express certain proteins that resist the activation of the apoptotic cascade. An example of pro survival protein that has been seen over expressed in various different cancers is $\mathrm{Bcl}-2$. Bcl-2 comprises of both anti- apoptotic (Bcl-2, BclXL, Mcl-1, CED-9, A1, Bfl-1) and pro-apoptotic (Bax, Bak,
Bcl-X3) family members. These over expressions are visualized by researchers using a molecular biology method known as immunohistochemistry [22].

\section{Cellular Hallmark No. 5 Sustained Proliferation}

Growth factor signaling in normal cells provides for the control of cellular and tissue homeostasis. Due to the over active oncogenes and the hallmarks discussed earlier cancer cells gain the ability to proliferate uncontrollably. Further these cancer cells can stimulate the normal cells present in the micro environment to provide growth factors [23]. EGF or the epidermal growth factor is one such factor that has been studied extensively in cancer research. EGF binds to the receptor present on the cancer cells known as EGFR and leads to the activation of an oncogene called RAS. RAS is responsible for promoting pro angiogenic activities in the tumor micro environment and alter the immune responses mediated by the host. RAS also regulates cellular adhesion which makes the cancer invasive and metastatic [24].

\section{Cellular Hallmark No. 6 Altered Metabolism}

As cancer cells sustain uncontrolled cell proliferation, it is vital for them to adjust their energy production. Cancer cells do so by finding and employing substitute sources of energy and metabolic pathways. Normal cells convert glucose to pyruvate which leads to the production of ATP molecules as energy. On the other hand cancer cells tend to behave differently. These cells irrespective of oxygen convert glucose to lactate. Cancer cells use this capability to detract metabolites required for essential and important anabolic processes such as mitosis [25]. Warburg et al. in the 1920s studied cancer cell metabolism in comparison to a normal cell metabolism and this came to be known as the Warburg effect. Warburg et al. stated the known following characteristics for metabolism in a normal cell: Oxidative phosphorylation, high ATP: Glucose ratio and low LDH activity resulting in high energy production and when compared with the metabolism of a cancer cell following characteristics were stated: Aerobic glycolysis, low ATP: glucose ratio and high LDH activity in one direction which leads to biomass incorporation and uncontrolled growth of cells [26].

\section{Cellular Hallmark No. 7 Avoid Immune Destruction}

The immune system is responsible for keeping a strict check in the human body and destroys all foreign cells, viruses, pathogens and tumor cells. B cells (responsible for secreting antibodies and cytokines), $\mathrm{T}$ lymphocytes, macrophages and natural killer cells are the cells of the immune system that engulf and destroy all foreign invaders. Cancer cells inhibit $\mathrm{T}$ cells which attack tumor cells, to protect themselves from the immune responses of the body by up regulating a protein known as programmed death ligand 1 (PDL1). PDL1 and PDL2 are transmembrane proteins responsible for suppressing the immune system in events such as autoimmune disorders, hepatitis and pregnancy. Immune system reacts to foreign 


\section{International Journal of Engineering Applied Sciences and Technology, 2020 \\ Vol. 5, Issue 4, ISSN No. 2455-2143, Pages 355-359 \\ Published Online August 2020 in IJEAST (http://www.ijeast.com)}

antigens and cells to trigger proliferation of CD8 T cells. In order to prevent auto immunity $\mathrm{T}$ cells express PDL1 which serve as a checkpoint for signaling the $\mathrm{T}$ cells to stop proliferating. Cancer cells prevent an attack from $\mathrm{T}$ cells by up regulating PDL1 and interacting with PD-1 thereby evading the immune system [27, 28].

\section{Cellular Hallmark No. 8 Tumor Promoting inflammations} Cancer cells take over the mechanisms of inflammation to promote their growth and proliferation. The cells from the immune system often enter the tumor micro environment and mimic inflammatory conditions observed in normal cells. These immune cells encourage the tumor cells to invade, proliferate uncontrollably and undergo epithelial to mesenchymal transition by providing them with growth factors [29].

\section{Cellular Hallmark No. 9 Induction of Angiogenesis}

Tumor cells require a continuous supply of blood and oxygen in order to grow and thrive. Cancer cells do so by initiating the development and formation of new blood vessels from the existing ones. Vascular endothelial growth factors (VEGFs) and various other pro angiogenic growth factors are activated in the tumor cells that are responsible for signaling endothelial cell proliferation and growth of blood vessels [30]. Angiogenesis is responsible for tumor expansion and invasion by providing tumor cells with oxygen, growth factors and nutrients thereby promoting tumor growth. As the process of angiogenesis is not a natural one, blood vessels are often poorly developed and are leaky. Due to these leaks it is very easy for the tumor cells to ooze out and cause metastasis [31].

\section{Cellular Hallmark of Cancer No. 10 Activation of Invasion and Metastasis}

Metastasis in initiated due to various reasons such as epithelial to mesenchymal transition, changes or loss of proteins such as integrins, loss of anti metastatic genes such as KAI1, CD82, NDRG1, immune cell recruitment and alterations in interactions between cells. Metastais is one of the major reasons of mortality among patients of cancer [32].

\section{METASTASIS}

Metastasis is referred to as the spread of cancer from the primary site of tumor development to the secondary site in the body through lymph or blood. Metastatic tumors have the ability to spread in the body and cause cancer development at various distant sites in the body where as benign tumors are a mass of cells that don't have the ability to invade the neighboring tissues or cells [33]. The term metastasis has been found in various writings and literatures in the $18^{\text {th }}$ century used to describe tumors in lactating women with breast cancer (Gould and Pyle, 1898). Metastasis was first used in 1829 by a French surgeon J. C. Recamier in context of treatment and diagnosis. Further in 1858, Rudolf Virchow, a German doctor described tumor dissemination stating that all solid tumors have the capability to metastasize and most people who die of cancer will possess a metastatic lesion. The major reasons for high mortality rates in cases of metastatic cancer includes, but are not limited to loss of tissue function in the metastatic site, internal bleedings, pulmonary embolism due to tumors, infections due to a weak immune response caused by treatment and cancer itself, cachexia and ion homeostatic disruption [34]. Though it has been proved that most cancer deaths are caused due to the process of metastasis, it is historically evident that people with limited metastasis have been treated and cured. Therefore, in 1994 this condition of limited metastatic potential was termed as oligometastasis. As treatment and imaging capabilities are increasing and improving more and more patients are being designated as oligometastaic [35].

\section{Key steps in metastasis:}

The process of metastasis follows some key steps:
I. Invasion
II. Intravasation
III. Survival during systemic circulation
IV. Extravasation

As tumor cells break through the extracellular matrix during invasion, they migrate outwardly away from their natural location. This allows the cancer cells to move towards the blood vessels (Invasion). As cancer cells enter the blood stream they might do it by pushing their way through endothelial cells or by entering through the leaky blood vessels originating as a result of angiogenesis (Intravasation). While travelling across various bodily systems such as the venous system, arterial system and lungs the tumors circulating in the bloodstream also referred to as circulating tumor cells or CTCs need to overcome and avoid various sources of cellular death (Survival during systemic circulation). When the cells are out from the lymphatic system they start developing and growing at a distant site or organ. These cells start growing and convert into metastatic tumors. There are possibilities that these cells may not start dividing immediately after getting onto their destination. They might go dormant forever and never grow or might grow into a tumor later (Extravasation) [36].

\section{CONCLUSION}

Hanahan and Weinberg have tried to assess the complexity of a very complicated and large field of cancer research in detail and develop a piece of literature capable of narrowing down these complexities for researchers, academicians and students involved in advanced areas of cancer research. Though critics have pointed out significant discrepancies such as an articles in Nature Reviews Cancer in 2010 argued that the hallmarks were common for both benign and metastatic tumors except for the ability of malignant tumors to invade and 


\section{International Journal of Engineering Applied Sciences and Technology, 2020 \\ Vol. 5, Issue 4, ISSN No. 2455-2143, Pages 355-359 \\ Published Online August 2020 in IJEAST (http://www.ijeast.com)}

metastasize. Another article in the Journal of Biosciences published in 2013 argues that all these hallmarks lack original data and stated that cancer is a tissue level disease and the cellular nature of these hallmarks are wrong and misleading. This review has been written and designed on the basis of the published work of Hanahan and Weinberg and various other researchers to further simplify the scientific literature for the understanding of beginner level researchers looking for simpler literature that provides a simpler understanding for the basics of cancer, that is, Hallmarks and Metastasis.

\section{ACKNOWLEDGEMENT}

We would like to extend our sincere gratitude to our parents and mentors for their continuous support and suggestions.

Conflict of Interest: The authors declare no conflict of interest.

\section{REFERENCE}

[1] [1] Blackadar CB.2016. Historical review of the causes of cancer. World J Clin Oncol. (pp. 54-86).

[2] [2] Wong RS. 2011. Apoptosis in cancer: from pathogenesis to treatment. J Exp Clin Cancer (pp.87).

[3] [3] Li QX, Yu DH, Liu G, Ke N, McKelvy J, Wong-Staal F. 2008. Selective anticancer strategies via intervention of the death pathways relevant to cell transformation. Cell Death Differ. (pp. 1197-210).

[4] [4] Fulda S, Debatin KM. 2006. Extrinsic versus intrinsic apoptosis pathways in anticancer chemotherapy. Oncogene. (pp. 4798-4811).

[5] [5] Bray F, Ren JS, Masuyer E. 2013. Estimates of global cancer prevalence for 27 sites in the adult population in 2008. Int J Cancer. (pp. 1133-1145).

[6] [6] Jha P, Jacob B, Gajalakshmi V, Gupta PC, Dhingra N, Kumar R. 2008. A nationally representative case-control study of smoking and death in India. New England Journal of Medicine. (pp. 1137-1147).

[7] [7] Sinha DN, Palipudi KM, Gupta PC, Singhal S, Ramasundarahettige C, Jha P. 2014. Smokeless tobacco use: a meta-analysis of risk and attributable mortality estimates for India. Indian Journal of Cancer. (pp.73-77).

[8] [8] Report on causes of deaths in India 2001-2003. Office of the Registrar General of India, Govt.of India, 2010.

[9] [9] WHO Summary report on HPV \& cervical cancer statistics in India (18/03/2008)

[10] [10] Singh M, Prasad CP, Singh TD, Kumar L. 2018. Cancer research in India: Challenges \& opportunities. Indian J Med Res. (pp. 362-365).

[11] [11] Chatterjee P. 2007. India addresses maternal deaths in rural areas. Lancet. (pp. 1023-1024).
[12] [12] Hanahan D, Weinberg RA. 2011. Hallmarks of cancer: the next generation. Cell. (pp. 646-674).

[13] [13] Hanahan D, Weinberg RA. 2000. The hallmarks of cancer. Cell. (pp. 57-70).

[14] [14] Hayflick L. 1997. Mortality and immortality at the cellular level. A review. Biochemistry (Mosc) . (pp. 118090).

[15] [15] Bryan TM, Englezou A, Gupta J, Bacchetti S, Reddel RR. 1995. Telomere elongation in immortal human cells without detectable telomerase activity. EMBO J. (pp.4240-4248).

[16] [16] Yao Y, Dai W. 2014. Genomic Instability and Cancer. J Carcinog Mutagen.

[17] [17] Chakravarthi BV, Nepal S, Varambally S. 2016. Genomic and Epigenomic Alterations. Cancer. Am J Pathol. (pp.1724-1735).

[18] [18] Lee EY, Bookstein R, Young LJ, Lin CJ, Rosenfeld MG, Lee WH. 1988. Molecular mechanism of retinoblastoma gene inactivation in retinoblastoma cell line Y79. Proc Natl Acad Sci U S A. (pp.6017-6021).

[19] [19] Fridman, J., Lowe, S. 2003. Control of apoptosis by p53. Oncogene 22, 9030-9040.

[20] [20] Wang LH, Wu CF, Rajasekaran N, Shin YK. 2018. Loss of Tumor Suppressor Gene Function in Human Cancer: An Overview. Cell Physiol Biochem. (pp. 26472693).

[21] [21] Vogelstein B, Papadopoulos N, Velculescu VE, Zhou S, Diaz LA Jr, Kinzler KW. 2013. Cancer genome landscapes. Science. (pp. 1546-1558).

[22] [22] Korsmeyer SJ, Shutter JR, Veis DJ, Merry DE, Oltvai ZN. 1993. Bcl-2/Bax: a rheostat that regulates an anti-oxidant pathway and cell death. Semin Cancer Biol. (pp.327-332).

[23] [23] Feitelson, Mark \& Arzumanyan, Alla \& Kulathinal, Rob \& Blain, Stacy \& Holcombe, Randall \& Mahajna, Jamal \& Marino, Maria \& Martinez chantar, Maria \& Nawroth, Roman \& Sanchex-Garcia, Isidro \& Sharma, Dipali \& Saxena, Neeraj \& Singh, Neetu \& Vlachostergios, Panagiotis \& Guo, Shanchun \& Asea, Alexzander \& Honoki, Kanya \& Fujii, Hiromasa \& Georgakilas, Alexandros \& Nowsheen, Somaira. (2015). Sustained Proliferation in Cancer: Mechanisms and Novel Therapeutic Targets. Seminars in Cancer Biology. (pp. 25-54).

[24] [24] Pylayeva-Gupta, Y., Grabocka, E. \& Bar-Sagi, D. 2011. RAS oncogenes: weaving a tumorigenic web. Nat Rev Cancer 11. (pp. 761-774).

[25] [25] Zhang Y, Yang JM. Altered energy metabolism in cancer: a unique opportunity for therapeutic intervention.2013. Cancer Biol Ther. (pp. 81-89). 
[26] [26] Warburg O, Wind F, Negelein E. 1927. THE METABOLISM OF TUMORS IN THE BODY. J Gen Physiol. (pp. 519-530).

[27] [27] Gonzalez H, Hagerling C, Werb Z. 2017. Roles of the immune system in cancer: from tumor initiation to metastatic progression. Genes Dev. (pp. 1267-1284).

[28] [28] Ostrand-Rosenberg S.2008. Immune surveillance: a balance between protumor and antitumor immunity. Curr Opin Genet Dev. (pp.11-18).

[29] [29] Mantovani A, Pierotti MA. 2008. Cancer and inflammation: a complex relationship. Cancer Lett. (pp. 180-181).

[30] [30] Shibuya M. 2011. Vascular Endothelial Growth Factor (VEGF) and Its Receptor (VEGFR) Signaling in Angiogenesis: A Crucial Target for Anti- and ProAngiogenic Therapies. Genes Cancer. (pp.1097-1105).

[31] [31] Nishida N, Yano H, Nishida T, Kamura T, Kojiro M. 2006. Angiogenesis in cancer. Vasc Health Risk Manag. (pp. 213-219).

[32] [32] Zavyalova MV, Denisov EV, Tashireva LA, Savelieva OE, Kaigorodova EV, Krakhmal NV, Perelmuter VM. 2019. Intravasation as a Key Step in Cancer Metastasis. Biochemistry (Mosc). (pp. 762-772).

[33] [33] Huysentruyt, Leanne. (2013). On the Origin of Cancer Metastasis. Critical reviews in oncogenesis. (pp. 43-73).

[34] [34] Zaorsky NG, Churilla TM, Egleston BL, Fisher SG, Ridge JA, Horwitz EM, Meyer JE. 2017. Causes of death among cancer patients. Ann Oncol. (pp.400-407).

[35] [35] Treasure T. 2012. Oligometastatic cancer: an entity, a useful concept, or a therapeutic opportunity? J R Soc Med. (pp.242-246).

[36] [36] van Zijl F, Krupitza G, Mikulits W. 2011. Initial steps of metastasis: cell invasion and endothelial transmigration. Mutat Res. (pp.23-34). 